\title{
Giant synovial cyst of knee treated arthroscopically through a cystic portal
}

Gautam M. Shetty $\cdot$ Joon Ho Wang $\cdot$ Jin Hwan Ahn
Yong Seuk Lee $\cdot$ Baek Hyun Kim $\cdot$ Jae Gyoon Kim

Published online: 9 January 2008

(C) Springer-Verlag 2008

Erratum to: Knee Surg Sports Traumatol Arthrosc

DOI 10.1007/s00167-007-0405-x

Unfortunately, we had indicated the wrong first name of the fourth author. The correct name is Yong Seuk Lee as now given above.

The online version of the original article can be found under doi:10.1007/s00167-007-0405-x.

G. M. Shetty · Y. S. Lee · J. G. Kim

Department of Orthopaedic Surgery,

Korea University Ansan Hospital, Ansan, South Korea

J. H. Wang ( ()

Department of Orthopaedic Surgery,

Korea University Ansan Hospital, \# 516, Gogan-Dong,

Ansan City, Gyeong gi-Do 425-707, South Korea

e-mail: mdwang@korea.ac.kr

J. H. Ahn

Department of Orthopaedic Surgery, Samsung Medical Center,

Sungkyunkwan University, Seoul, South Korea

B. H. Kim

Department of Radiology,

Korea University Ansan Hospital, Ansan, South Korea 